\title{
INTERVENTION EFFECT AND DOSE-DEPENDENT RESPONSE OF TANREQING INJECTION ON AIRWAY
} MUCUS HYPERSECRETION IN LIPOPOLYSACCHARIDE-INDUCED RATS

\section{Shou-jin Dong ${ }^{1,2}$, Yun-qing Zhong ${ }^{3}$, Wen-ting Lu ${ }^{4}$, Kun Yang ${ }^{5}$, Mao-juan Liu ${ }^{4}$, Xiao-ling Xiong ${ }^{4}$, Bing Mao $^{1}$}

${ }^{1 .}$ Department of Integrated Traditional Chinese and Western Medicine, West China Hospital, West China Medical School, Sichuan University, Chengdu, 610041, China. ${ }^{2 .}$ Department of Pneumology, Chengdu First People's Hospital, Chengdu Integrated Traditional Chinese and Western Medicine Hospital, Chengdu, 610041, China. ${ }^{3}$ Department of Pneumology, The First Affiliated Hospital of Guangxi Traditional Chinese Medical University, Nanning, 530023, China. ${ }^{4}$ Department of geratology, Sichuan Hospital of Integrated Traditional Chinese and Western Medicine, Chengdu, 610041, China ${ }^{5}$.Department of geratology, Chengdu University of Traditional Chinese Medicine, Chengdu, 610041, China.

Both authors, Dong SJ, Zhong YQ and Lu WT contributed equally to this article. Correspondence should be addressed to Mao B, E-mail: wumingshoujin@ sina.com,

\begin{abstract}
Background: Tanreqing injection, a Chinese herbal formulation comprising Radix Scutellariae, Fructus Forsythiae, Flos Lonicerae, Antelope horn, and Bear bile powder, has been used to treat bronchitis and pneumonia for many years in China. However, its anti-mucus-hypersecretion mechanism has yet not been fully interpreted. We aim to assess the effect and dose-response relationships of Tanreqing injection on lipopolysacchaide (LPS) induced airway mucus hypersecretion in rats.

Material and methods: Forty-eight male rats were randomly divided into four groups (12 per group). A rat model of airway mucus hypersecretion was generated with LPS. Tanreqing injection was given by intratracheal instillation, and bronchoalveolar lavage fluid (BALF) from the right lung was collected. BALF total protein was determined by bicinchoninic acid disodium assay (BCA). Muc5ac was measured using enzyme linked immunosorbent assay (ELISA) and immunohistochemistry. The expression of muc5ac mRNA was detected by real-time polyermase chain reaction (RT-PCR). The middle lobe of the right lung was stained with alcian blue-periodic acid sthiff (AB-PAS) and positive staining relative shading area examined.
\end{abstract}

Results: LPS caused airway mucus hypersecretion, The LPS-induced airway mucus hypersecretion increased beginning at 24 hr, and peaked at $96 \mathrm{hr}$. Tanreqing injection could inhibit airway mucus hypersecretion, and suppress the expression of muc5ac mRNA.

Conclusion: Tanreqing injection inhibits airway mucus hypersecretion in a certain dose-dependent trend.

Key words: Tanreqing injection, lipopolysaccharides, airway mucus hypersecretion, dose-response relationship.

\section{Abbreviations}

COPD, Chronic obstructive pulmonary disease; LPS, Lipopolysaccharide; RT-PCR, Real-time polyermase chain reaction; ELISA, Enzymelinked immunosorbent assay; NS, Normal saline; BALF, Bronchoalveolar lavage fluid; BCA, Bicinchoninic acid disodium assay; AB-PAS, alcian blue-periodic acid sthiff. 


\section{Introduction}

Chronic obstructive pulmonary disease (COPD) is a major cause of chronic morbidity and readmission rate worldwide (GOLD., 2013). COPD is characterized by continuous airway inflammation and mucus hypersecretion (Lai et al., 2010). Airway mucus hypersecretion plays an important role in COPD pathophysiology with goblet cells hyperplasia and submucosal gland enlargement. The lung function progressive and irreversible lost with airway mucus hypersecretion continues (Rogers et al., 2007).

Expectorants (such as anti-cholinergic agents, corticosteroid, long-term epinephrine agonists, and so on) were often used to treat airway mucus hypersecretional diseases by attenuating sputum. But the curative effect of expectorants was uncertain. More and more research results showed that the traditional Chinese medicine (TCM) could improved clinical efficacy of COPD patients (Li et al., 2010; Zhang et al., 2004; Zhong et al., 2010; Jiang et al., 2009). Western medicine treatment combined with TCM treatment is becoming one of the major treatments for AECOPD (Li et al., 2010; Zhang et al., 2004). At present, Tanreqing injection has become one of the representative drugs for AECOPD.

Tanreqing injection, a Chinese herbal formulation comprising Radix Scutellariae, Fructus Forsythiae, Flos Lonicerae, Antelope horn, and Bear bile powder, has been used to treat acute bronchitis and acute pneumonia for many years in China. A large number of clinical studies and systematic reviews showed that Western medicine treatment plus Tanreqing injection could improved the clinical symptoms of AECOPD patients (Li et al., 2010; Zhang et al., 2004; Zhong et al., 2010; Jiang et al., 2009).

In this study, we selected Tanreqing injection as intervention to study the intervention effect of TCM on airway mucus hypersecretion. We aimed to observe the dynamic changes of LPS-induced airway mucus hypersecretion in rat, to explore Tanreqing injection on LPS-induced airway mucus hypersecretion rat intervention effect and dose-response relationships.

\section{Materials and methods}

\section{Preparation of Tanreqing injection}

Tanreqing injection, producted by Shanghai Kaibao Pharmaceutical Co.,Ltd. of China with country medicine accurate character Z20030054, is a Chinese Materia Medica standardized product which consisted of Radix Scutellariae (Scutellaria baicalensis Georgi, huangqin), Fructus Forsythiae (Forsythia suspensa /Thunb. Vahl, lianqiao), Flos Lonicerae (Lonicera japonica Thunb., jinyinhua), Antelope horn, and Bear bile powder. The main active components of Tanreqing injection are the phenols such as Baicalin, Chlorogenic acid, Forsythia glycosides, Keratin, Bile acids such as Taurocholic ursodeoxycholic acid, Taurocholic chenodeoxycholic acid. The low and high doses of Tanreqing injection were defined by the published literatures and animal body weight dose conversion coefficient (Deng et al., 2011; Shi et al., 1989).

\section{Reagents}

Lipopolysaccharide escherichia coli 055:B5, paraformaldehyde and DEPC were purchased from Sigma (USA), pierce BCA protein assay kit was purchased from Thermo Scientific (USA), rat muc5ac ELISA kit was purchased from Youersheng company (Wuhan, China), muc5ac mouse monoclonal antibody was purchased from NeoMarkers (USA), the biotinylated horse-anti-mouse IgG (H+ L) and horseradish peroxidase streptavidin were purchased from Zhongshan Golden Bridge Biotechnology Co., Ltd. (Beijing, China), DAB color kit was purchased from Boshide company (Wuhan, China), trizol was purchased from MRC (USA), revert aid ${ }^{\mathrm{TM}}$ first strand cDNA synthesis kit was purchased from Fermentas (USA), TaqDNA polymerase and dNTP were purchased from TaKaRa (Japan), primers and probes were purchased from Sangon Biotech Co.,Ltd. (Shanghai, China).

\section{Experimental animals}

Specific pathogen free adult male Sprague-Dawley rats, weighting $200 \sim 250$ g, were purchased from the Bill Animal Farm of Jianyang (Jianyang, China). All rats were adaptively fed for 5 days. 


\section{Model Preparation}

The rat airway mucus hypersecretion model was prepared according to the modeling method of Ou et al. (Ou et al., 2008) with modifications. Rats were anesthetized by intraperitoneal injection of $4 \%$ pentobarbital sodium ( $40 \mathrm{mg} / \mathrm{kg})$ and fixed on a rat board. After local disinfection, a neck midline incision of $1.5 \mathrm{~cm}$ was made by blunt separation to expose the trachea. The trachea was punctured with a 1 -mL syringe and $120 \mu \mathrm{L}(2 \mathrm{~g} / \mathrm{L})$ LPS was slowly injected into the airway, once per rat. Rats were gently shaken upright for about 2 min to uniformly distribute LPS in the lungs. The neck skin was then sutured and disinfected.

\section{Experimental methods}

The rats were randomly divided into four groups with the random number table: blank control, model, low dose Tanreqing intervention, and high dose Tanreqing intervention groups (12 rats in each group). The low and high dose Tanreqing groups were defined with respect to the published animal weight and dose conversion factors. Rats in blank control group were injected normal saline (NS) via trachea, while rats in model group and drug treatment groups were injected LPS via trachea to establish airway mucus hypersecretion models. After rats drug treatment groups were injected Tanreqing injection intraperitoneally at the dose of $2.8 \mathrm{~mL} / \mathrm{Kg}$ and $5.6 \mathrm{~mL} / \mathrm{Kg}$ respectively, while blank control group and model group were administered the same amount of NS instead. Rats were random sacrificed (4 /group/batch) at 24, 48, and 96 hr after airway injection of NS or LPS.

\section{Specimen collection}

Rats were anesthetized intraperitoneally with $4 \%$ pentobarbital sodium and then sacrificed by exsanguination from the femoral artery. The trachea was cannulated by injector needle, and the chest cavity was opened by a midline incision. The right upper lobe was stored in liquid nitrogen for RNA extraction. The right middle lobe was fixed in $4 \%$ paraformaldehyde buffer ( $\mathrm{pH} 7.4$ ) and embedded in paraffin for morphometric and immunohistochemical analysis. The right main-stem bronchus was ligated, and the left lung was lavaged with $2 \mathrm{~mL}$ sterilizing NS followed by 3 times for bronchoalveolar lavage fluid (BALF). Fluid recovery was always above $90 \%$. The BALF samples were centrifuged at $4000 \mathrm{rpm}$ for $5 \mathrm{~min}$, and then the supernatants were removed to EP tubes and stored at $-80{ }^{\circ} \mathrm{C}$ for protein and Muc5ac mucin quantification.

\section{Airway histopathological morphological analysis}

Airway tissue was fixed in $4 \%$ paraformaldehyde buffer (pH 7.4$)$ and embedded in paraffin. Paraffin sections (4 $\mu$ m) were stained with alcian blue (AB) and periodic acid-schiff (PAS). All the sections were prepared for routine histological evaluation. The pathological changes were detected by light microscopy (Olympus, CKX41) and photographic recorded ( $\times 400)$. The degree of inflammatory cell infiltration was assessed. Pictures of five complete airways were randomly taken with SPOT Advanced and percentages of positively stained areas by AB/PAS to the total airway epithelial area were measured by Image-Pro Plus 5.0 software.

\section{Detection of muc5ac expression by immunohistochemical assay}

Sections were prepared from each lung and mounted on routine slides. The paraffin sections were deparaffinized by normal method, followed by blocking of endogenous peroxidase activity with $0.3 \% \mathrm{H}_{2} \mathrm{O}_{2}$ for $10 \mathrm{~min}$, and washed with distilled water 3 times. The slices were immersed in $0.01 \mathrm{~mol} / \mathrm{L}$ citrate buffer ( $\mathrm{pH} 6.0$ ) and heated by high-fire in the microwave oven to boil, then washed with cooled PBS ( pH 7.2 7.6 ) 2 times after the interval of $3 \mathrm{~min}$. The $0.5 \%$ BSA blocking buffer was added at room temperature for 10 minutes, and then excess liquid was shaked off. The primary antibody (dilution 1:100) was added overnight at $4{ }^{\circ} \mathrm{C}$. After being rinsed with PBS (pH 7.2 7.6) for 2 min 3 times, then the biotinylated horse-anti-mouse IgG (dilution 1:100) was added for $20 \mathrm{~min}$ at $37{ }^{\circ} \mathrm{C}$. After being rinsed with PBS (pH $7.2 \sim 7.6$ ) for 2 min 
Dong et al., Afr J Tradit Complement Altern Med. (2015) 12(3):173-182

http://dx.doi.org/10.4314/ajtcam.v12i3.22

3 times, the horseradish peroxidase streptavidin ( dilution 1:100) was added for 20 min at $37{ }^{\circ} \mathrm{C}$. After being rinsed for 5 min 4 times with PBS, the sections were stained with DAB coloration kit. The sections were stained lightly by hematoxylin, mounted and then examined under the microscope (Olympus, CKX41). Pictures were taken by SPOT Advanced software and IOD were detected by image-pro plus 5.0 software for semi-quantitative analysis.

\section{Real-time- polymerase chain reaction analysis ( RT-PCR)}

Total RNA was isolated using a trizol reagent from the frozen lung tissue (weighting about $50 \mathrm{mg}$ ) according to the manufacturer's direction. Twentlve parts of of total RNA were randomly taken to do $1 \%$ agarose gel electrophoresis. The cDNA was synthesized by reverse transcription from $5 \mu \mathrm{L}$ of total RNA using revert aid ${ }^{\mathrm{TM}}$ frist strand cDNA synthesis kit. The reaction was carried out in a $20 \mu \mathrm{L}$ of final volume by using reverse transcription system and random hexamer primer $(0.2 \mu \mathrm{g} / \mu \mathrm{L})$ as the primer according to the manufacturer's direction. The products were stored at $-20{ }^{\circ} \mathrm{C}$ for cDNA templates. Then, the PCR amplification was performed in a total volume of $30 \mu \mathrm{L}$ containing $2 \mu \mathrm{L}$ of cDNA template, TaqMan probe $(10 \mu \mathrm{M}) 1 \mu \mathrm{L}$, Taq DNA polymerase $(5 \mathrm{u} / \mu \mathrm{L}) 0.3 \mu \mathrm{L}$. (see Table 1 ) PCR was performed for 45 cycles. Each cycle consisted of predenaturation for $2 \mathrm{~min}$ at $94{ }^{\circ} \mathrm{C}$, denaturation for $20 \mathrm{~s}$ at $94{ }^{\circ} \mathrm{C}$, annealing for $20 \mathrm{~s}$ at $56{ }^{\circ} \mathrm{C}$ and extension for $30 \mathrm{~s}$ at $60{ }^{\circ} \mathrm{C}$. Each PCR products were electrophoresed on the $2 \%$ agarose gel. The $\mathrm{Ct}$ value of each sample was automatically calculated by the computer at the end of each reaction, and the $\mathrm{Ct}$ values of the target gene and the reference gene were obtained to calculate the levels of relatively expression of muc5ac genes in each group.

Table 1: Primers for real-time PCR

\begin{tabular}{ll}
\hline \multicolumn{1}{c}{ Gene } & \multicolumn{1}{c}{ Primer } \\
\hline Muc5ac & Forward: 5'- CAATAACCACCCGGTCCAG -3' \\
& Reverse: 5' - CAACTCCAGCAGAAGACTGT -3' \\
& The probe: FAM-CCAGCCTGGCCACCACCTTC-TAMRA \\
& Forward: 5'-GAAGATCAAGATCATTGCTCCT-3' \\
& Reverse: 5' - TACTCCTGCTTGCTGATCCA -3' \\
& The probe: FAM-CTGTCCACCTTCCAGCAGA-TAMRA \\
\hline
\end{tabular}

\section{Statistical analysis}

The data were analyzed by SPSS 17.0 software (SPSS Inc., Chicago, IL, USA). Data were normally distributed and expressed as mean \pm SD. $P<0.05$ was regarded as statistically significant. Tests for normality and the analysis of variance (ANOVA) were adopted, assuming equal variance. If test results were statistically significant, the SNK method was adopted for future comparisons. Non-parameter tests were used for data assuming equal variance. A Chi-square test was used for comparison of multi-rates.

\section{Results}

\section{Effect of Tanreqing injection on the total protein and muc5ac in BALF}

There was no significant change of total protein and muc5ac in BALF in the blank control group at 24, 48, $96 \mathrm{hr}$. In the model group, the total protein and muc5ac in BALF increased beginning at $24 \mathrm{~h}$, increased gradually up to $48 \mathrm{hr}$, peaked at 96 hr. Compared with the model group, the total protein and muc5ac in BALF decreased in both the low and high dose Tanreqing intervention group, with no significant differences between the two groups. The high dose Tanreqing intervention more decreased BALF total protein and muc5ac than low dose, but no statistically significant $(P>0.05)$. (see Table 2, 3, Figure 1a, 1b) 
Dong et al., Afr J Tradit Complement Altern Med. (2015) 12(3):173-182

http://dx.doi.org/10.4314/ajtcam.v12i3.22

Table 2: Changes in total protein in $\operatorname{BALF}\left(\mu \mathrm{g} / \mathrm{mL}, \bar{x} \pm_{\mathrm{s}}\right)$

\begin{tabular}{lccc}
\hline \multicolumn{1}{c}{ Group } & $24 \mathrm{~h}$ & $48 \mathrm{~h}$ & $96 \mathrm{~h}$ \\
\hline Blank control & $168.79 \pm 29.40$ & $174.01 \pm 29.48$ & $180.72 \pm 31.04$ \\
Model & $296.02 \pm 33.08^{\mathrm{a}}$ & $409.27 \pm 112.23^{\mathrm{a}}$ & $514.42 \pm 126.78^{\mathrm{ad}}$ \\
Low dose Tanreqing intervention & $266.32 \pm 33.99^{\mathrm{e}}$ & $284.94 \pm 61.35^{\mathrm{b}}$ & $315.46 \pm 82.30^{\mathrm{b}}$ \\
High dose Tanreqing intervention & $245.13 \pm 28.98^{\mathrm{ec}}$ & $248.44 \pm 24.86^{\mathrm{bc}}$ & $254.16 \pm 86.96^{\mathrm{bc}}$ \\
\hline
\end{tabular}

Note: ${ }^{\mathrm{a}} \mathrm{P}<0.05$, compared with the blank control group at the same point; ${ }^{\mathrm{b}} \mathrm{P}<0.05$, compared with the model group at the same point; ${ }^{\mathrm{c}} \mathrm{P}>$ 0.05 , compared with the low dose Tanreqing intervention group at the same point; ${ }^{\mathrm{d}} \mathrm{P}<0.05$, compared with the same group at $24 \mathrm{~h}$; ${ }^{\mathrm{e}} \mathrm{P}>0.05$, compared with the model group at the same point.

Table 3: Changes in muc5ac in $\operatorname{BALF}(\mathrm{ng} / \mathrm{mL}, \bar{x} \pm \mathrm{s})$

\begin{tabular}{lccc}
\hline \multicolumn{1}{c}{ Group } & \multicolumn{1}{c}{$24 \mathrm{~h}$} & \multicolumn{1}{c}{$48 \mathrm{~h}$} & $96 \mathrm{~h}$ \\
\hline Blank control & $0.11 \pm 0.02$ & $0.13 \pm 0.01$ & $0.15 \pm 0.06$ \\
Model & $0.32 \pm 0.07^{\mathrm{a}}$ & $0.43 \pm 0.05^{\mathrm{a}}$ & $0.59 \pm 0.03^{\mathrm{ad}}$ \\
Low dose Tanreqing intervention & $0.20 \pm 0.06^{\mathrm{b}}$ & $0.28 \pm 0.04^{\mathrm{b}}$ & $0.35 \pm 0.07^{\mathrm{b}}$ \\
High dose Tanreqing intervention & $0.19 \pm 0.05^{\mathrm{bc}}$ & $0.21 \pm 0.08^{\mathrm{bc}}$ & $0.28 \pm 0.06^{\mathrm{bc}}$ \\
\hline
\end{tabular}

Note: ${ }^{a} \mathrm{P}<0.05$, compared with the blank control group at the same point; ${ }^{b} \mathrm{P}<0.05$, compared with the model group at the same point; ${ }^{c} \mathrm{P}>$ 0.05 , compared with the low dose Tanreqing intervention group at the same point; ${ }^{\mathrm{d}} \mathrm{P}<0.05$, compared with the same group at $24 \mathrm{~h}$; ${ }^{\mathrm{e}} \mathrm{P}>0.05$, compared with the model group at the same point.
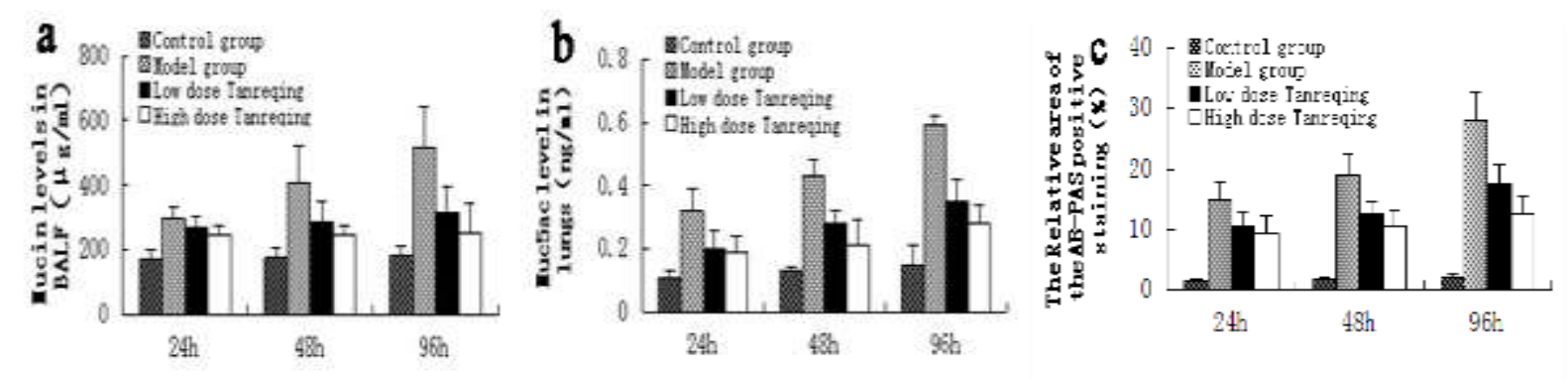

Figure 1: Levels of a ) mucin and b ) muc5ac in BALF. Mucin were determined by BAC and muc5ac were determined by ELISA. C ) The percentage of $\mathrm{AB} / \mathrm{PAS}$ positively staining area to total area in rat airways. Values are expressed as mean $\pm \mathrm{SD}$.

Effect of Tanreqing injection on histopathological changes in rat airways reduced by LPS

Histopathological changes of rat airways were detected by AB-PAS. In the blank control group, positively stained areas was few with no significant differences at $24,48,96 \mathrm{hr}$. In the model group, the positively stained areas increased beginning at $24 \mathrm{hr}$, increased gradually up to 48 hr, peaked at $96 \mathrm{hr}$. Compared with the model group, the positively stained areas decreased in both the low and high dose Tanreqing intervention group. The high dose Tanreqing intervention more decreased BALF total protein and muc5ac than low dose, but no statistically significant $(P>$ 0.05). (see Table 4, Figure 1c, 2) 
Dong et al., Afr J Tradit Complement Altern Med. (2015) 12(3):173-182

http://dx.doi.org/10.4314/ajtcam.v12i3.22

Table 4: Changes in the AB-PAS positively stained areas in rat airway( $\%, \bar{x} \pm \mathrm{s})$

\begin{tabular}{lccc}
\hline \multicolumn{1}{c}{ Group } & $24 \mathrm{~h}$ & $48 \mathrm{~h}$ & $96 \mathrm{~h}$ \\
\hline Blank control & $1.56 \pm 0.34$ & $1.75 \pm 0.27$ & $2.13 \pm 0.42$ \\
Model & $15.05 \pm 2.77^{\mathrm{a}}$ & $18.96 \pm 3.61^{\mathrm{a}}$ & $28.02 \pm 4.56^{\mathrm{ad}}$ \\
Low dose Tanreqing intervention & $10.45 \pm 2.34^{\mathrm{b}}$ & $12.53 \pm 2.21^{\mathrm{b}}$ & $17.50 \pm 3.36^{\mathrm{b}}$ \\
High dose Tanreqing intervention & $9.50 \pm 2.92^{\mathrm{bc}}$ & $10.59 \pm 2.75^{\mathrm{bc}}$ & $12.57 \pm 3.01^{\mathrm{bc}}$ \\
\hline
\end{tabular}

Note: ${ }^{\mathrm{a}} \mathrm{P}<0.05$, compared with the blank control group at the same point; ${ }^{\mathrm{b}} \mathrm{P}<0.05$, compared with the model group at the same point; ${ }^{\mathrm{c}} \mathrm{P}>0.05$, compared with the low dose Tanreqing intervention group at the same point; ${ }^{\mathrm{d}} \mathrm{P}<0.05$, compared with the same group at $24 \mathrm{hr}$.
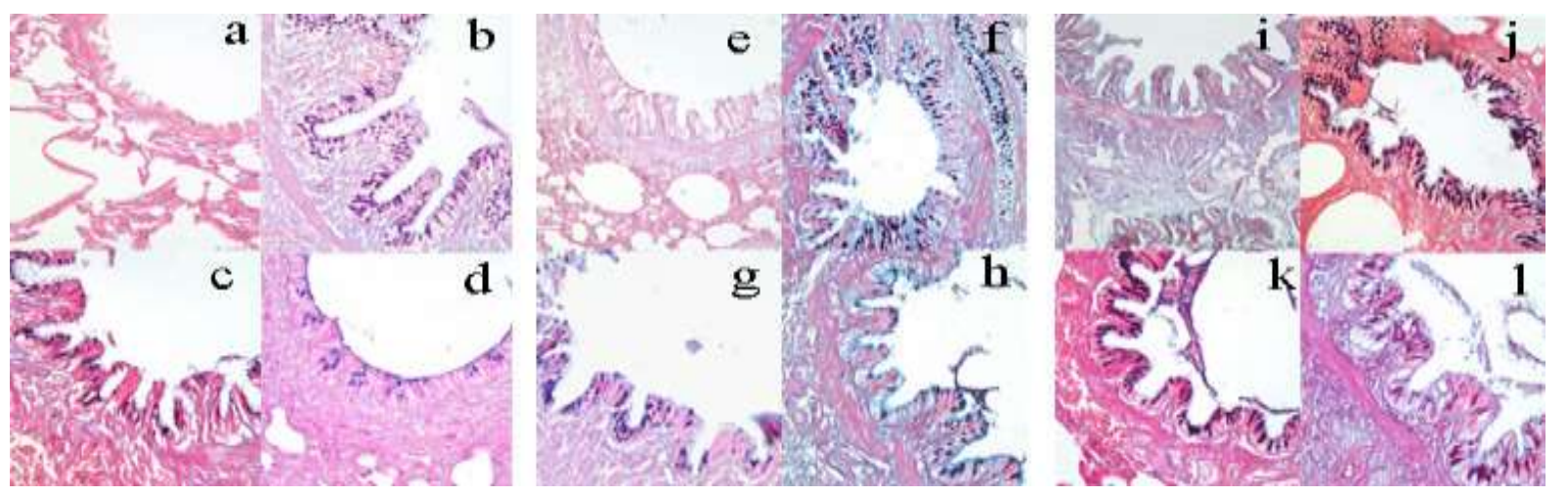

Figure 2: AB-PAS staining results of airway tissue in rats ( $x 400$ ). Histological changes in rat airway. Lung tissuses from the blank control group at hour a ) 24, e ) 48 and i ) 96; model group at hour b ) 24, f ) 48 and j ) 96; group with low dose Tanreqing at hour c ) 24, g) 48 and k) 96; group with high dose Tanreqing at hour d) 24, hr) 48 and l) 96 were analyzed by AB-PAS staining.

\section{Effect of Tanreqing injection on muc5ac expression}

In the blank control group, muc5ac positively stained granule was few with no significant differences at 24, 48, 96 hr. In the model group, the positively stained granule increased beginning at $24 \mathrm{hr}$, increased gradually up to $48 \mathrm{hr}$, peaked at $96 \mathrm{hr}$. Compared with the model group, the positively stained granule decreased in both the low and high dose Tanreqing intervention group. The high dose Tanreqing intervention more decreased BALF total protein and muc5ac than low dose, but no statistically significant $(P>0.05)$. (see Table 5, Figure 3,4a)

Table 5: Changes in the expression of muc5ac in rat airway( IDO $\times 10^{3}, \bar{x} \pm \mathrm{s}$ )

\begin{tabular}{lccc}
\hline \multicolumn{1}{c}{ Group } & \multicolumn{1}{c}{$24 \mathrm{~h}$} & $48 \mathrm{~h}$ & \multicolumn{1}{c}{$96 \mathrm{~h}$} \\
\hline Blank control & $0.53 \pm 0.09$ & $0.56 \pm 0.11$ & $0.63 \pm 0.19$ \\
Model & $45.05 \pm 5.88^{\mathrm{a}}$ & $85.87 \pm 8.77^{\mathrm{a}}$ & $134.49 \pm 20.06^{\mathrm{ad}}$ \\
Low dose Tanreqing intervention & $33.17 \pm 3.19^{\mathrm{b}}$ & $51.86 \pm 6.05^{\mathrm{b}}$ & $72.82 \pm 7.16^{\mathrm{b}}$ \\
High dose Tanreqing intervention & $27.82 \pm 4.53^{\mathrm{bc}}$ & $42.93 \pm 4.96^{\mathrm{bc}}$ & $56.74 \pm 4.60^{\mathrm{bc}}$ \\
\hline
\end{tabular}

Note: ${ }^{\mathrm{a}} \mathrm{P}<0.05$, compared with the blank control group at the same point; ${ }^{b} \mathrm{P}<0.05$, compared with the model group at the same point; ${ }^{\mathrm{c}} \mathrm{P}>0.05$, compared with the low dose Tanreqing intervention group at the same point; ${ }^{\mathrm{d}} \mathrm{P}<0.05$, compared with the same group at $24 \mathrm{hr}$. 


\section{Dong et al., Afr J Tradit Complement Altern Med. (2015) 12(3):173-182}

http://dx.doi.org/10.4314/ajtcam.v12i3.22
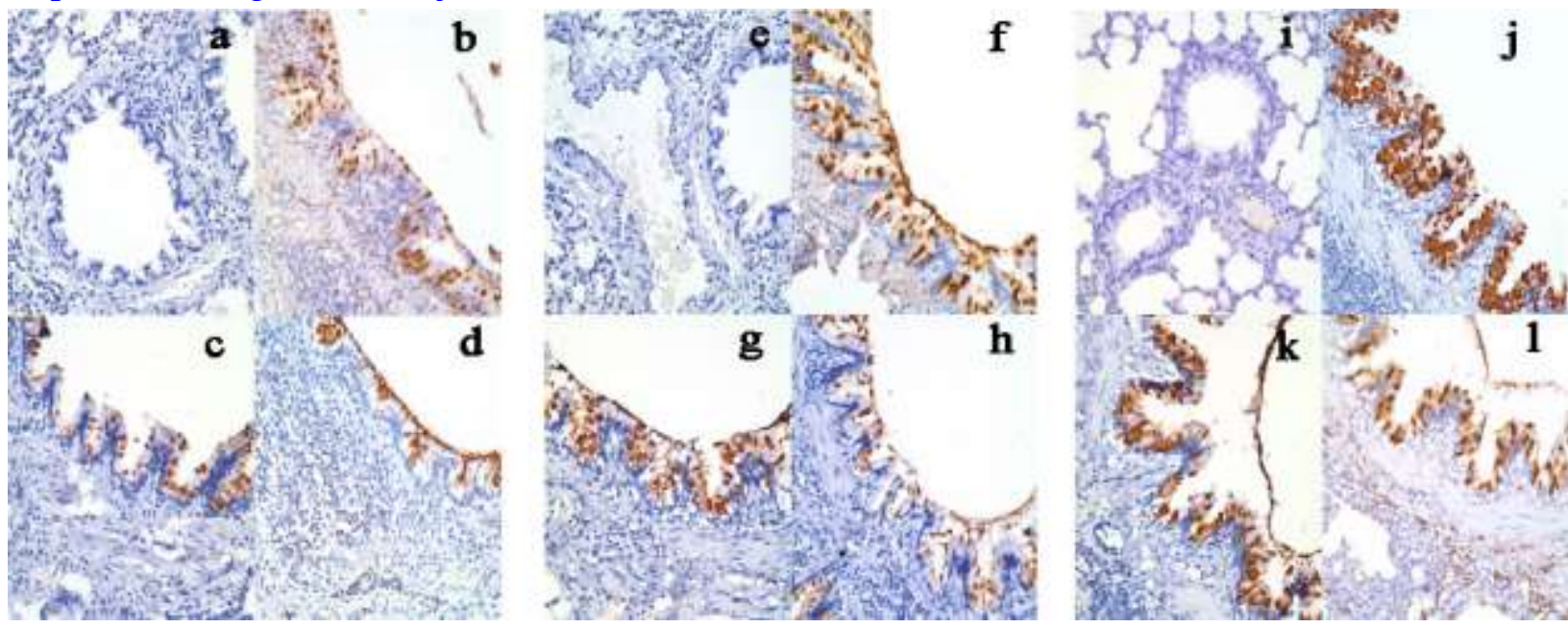

Figure 3: Muc5ac immunohistochemical results of rat airways ( $\times 400)$. Lung tissuses from the blank control group at hour a) 24 , e) 48 and i) 96 ; model group at hour b) 24, f) 48 and j) 96; group with low dose Tanreqing at hour c) 24, g) 48 and k) 96; group with high dose Tanreqing at hour d) 24, hr) 48 and 1) 96 were analyzed by muc5ac immunohistochemistry.

\section{Effect of Tanreqing injection on muc5ac mRNA expression by real-time PCR}

In the blank control group, the expression of muc5ac mRNA was low with no significant differences at $24,48,96 \mathrm{hr}$. In the model group, the expression of muc5ac mRNA increased beginning at $24 \mathrm{hr}$, increased gradually up to $48 \mathrm{hr}$, peaked at $96 \mathrm{hr}$. Compared with the model group, the expression of muc5ac mRNA decreased in both the low and high dose Tanreqing intervention group. The high dose Tanreqing intervention more decreased BALF total protein and muc5ac than low dose, but no statistically significant $(P>0.05)$. (See Table 6 , Figure 4 )

Table 6: Changes in the expression of muc5ac mRNA in rat lung $\left(\times 10^{-5}, \bar{x} \pm \mathrm{s}\right)$

\begin{tabular}{lccc}
\hline \multicolumn{1}{c}{ Group } & \multicolumn{1}{c}{$24 \mathrm{~h}$} & $48 \mathrm{~h}$ & $96 \mathrm{~h}$ \\
\hline Blank control & $4.31 \pm 1.30$ & $5.72 \pm 1.40$ & $5.88 \pm 2.62$ \\
Model & $62.99 \pm 19.58^{\mathrm{a}}$ & $115.03 \pm 16.84^{\mathrm{a}}$ & $284.59 \pm 80.32^{\mathrm{ad}}$ \\
Low dose Tanreqing intervention & $28.68 \pm 6.87 \mathrm{~b}$ & $61.76 \pm 9.60 \mathrm{~b}$ & $123.02 \pm 30.46 \mathrm{~b}$ \\
High dose Tanreqing intervention & $18.43 \pm 5.09^{\mathrm{bc}}$ & $50.31 \pm 14.20^{\mathrm{bc}}$ & $83.35 \pm 16.51^{\mathrm{bc}}$ \\
\hline
\end{tabular}

Note: ${ }^{\mathrm{a}} \mathrm{P}<0.05$, compared with the blank control group at the same point; ${ }^{b} \mathrm{P}<0.05$, compared with the model group at the same point; ${ }^{\mathrm{c}} \mathrm{P}>0.05$, compared with the low dose Tanreqing intervention group at the same point; ${ }^{\mathrm{d}} \mathrm{P}<0.05$, compared with the same group at $24 \mathrm{hr}$.
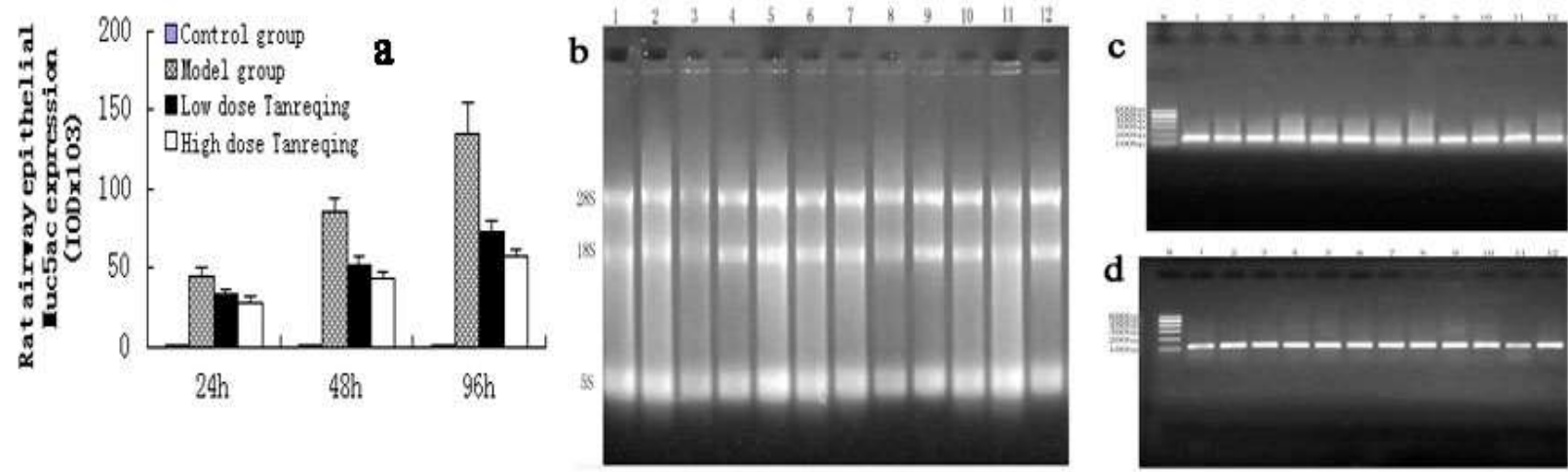

Figure 4: Changes of a) muc5ac on the expression, and the changes in mucin muc5ac mRNA and protein levels were measured by b) western blotting and the steady state of mRNA levels for muc5ac was analysed by c), d) reverse transcriptase PCR. Values are expressed as mean \pm SD. 


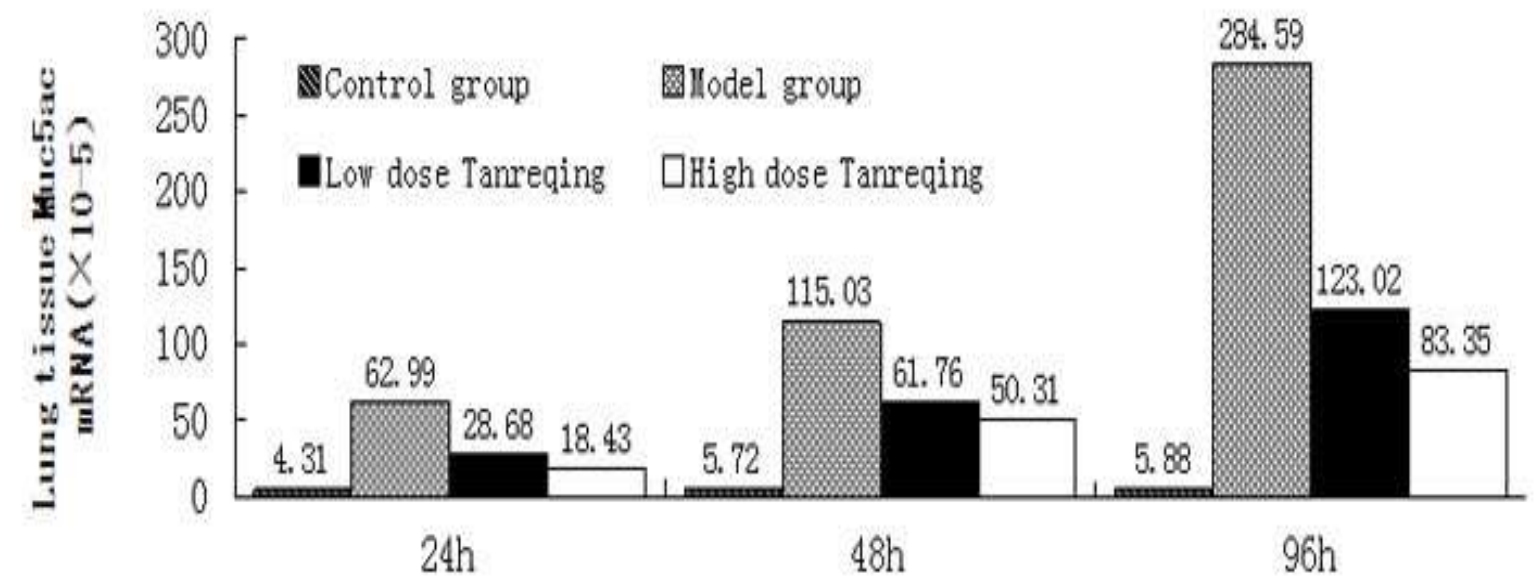

Figure 5: Lung tissue the muc5ac relative expression quantitative analysis diagram

\section{Discussion}

The choice of experimental animals and evaluation of airway mucus hypersecretion

Some scholars have used LPS injection to establish an airway mucus hypersecretion animal model (John et al., 2008; Xie et al., 2009; Yanagihara et al., 2001; Wesselius et al., 1997). In our previous period, we also have been successfully established the airway inflammation and mucus hypersecretion model according the modeling method of Ou et al (Ou et al., 2008) with modifications. In this study, we gave rats LPS to establish animal model with BALF total protein, muc5ac, the AB-PAS positive staining relative shading area and the expression of Muc5ac mRNA all significant increasing ( Figures 2, 3 ), indicating that an airway mucus hypersecretion model was established.

The choice of observation time points in the experiment

Yanagihara (Yanagihara et al., 2001) found the rat airway mucus hypersecretion induced by LPS reached a peak at 2nd day, 4th day a slight decreased and 7th day further reduced. It has recently been reported that the rat mucus hypersecretion induced by LPS peaked at 4th day with 2 nd day, 4th day, 7th day as the observation time (Chen et al., 2009; Yanagihara et al., 2001). If the observation time was too long, the animals would be susceptible to cross infection and affect the experimental results, and mortality would increase. So 168 hr (7th day) was not selected. According to our prepared experiments and published results, we selected 24, 48, and $96 \mathrm{hr}$ after LPS stimulation as observation points, to clearly define dynamic changes of LPS-induced airway mucus hypersecretion.

\section{Selection of indices of airway mucus hypersecretion}

Mucus composed of water, ions, proteins, lipids and mucin glycoproteins coats the luminal surface of the airway. So far, more than 20 MUC genes were isolated, such as MUC1, MUC2, MUC4, MUC5AC, MUC5B, MUC7, MUC8, MUC11, MUC13, MUC15, MUC19, MUC20, and so on. These genes were localized in the lower respiratory tract, but MUC5AC major in airway epithelium goblet cells. Muc1, Muc2 and Muc4 were expressed in rats conduction airway epithelium, and muc5ac in airway epithelium goblet cells (Rose et al., 2006). Muc5ac, the predominant mucin in mucus, was often selected as the indice of airway mucus hypersecretion by scholars. Muc5ac protein content of epithelial airway and mRNA transcription level could reflect the intensity of airway mucus hypersecretion (Zuhdi et al., 2000). In this study, muc5ac expression by immunohistochemical method and muc5ac mRNA expression by real-time quantitative PCR were detected for airway mucus hypersecretion indicators. 
Dong et al., Afr J Tradit Complement Altern Med. (2015) 12(3):173-182

http://dx.doi.org/10.4314/ajtcam.v12i3.22

Dynamic changes of rat airway mucus hypersecretion induced by LPS

The dynamic change in characteristics of airway mucus hypersecretion induced by LPS was conformed in this study. In the blank control group, the indices of airway mucus hypersecretion were low level with no significant differences at 24, 48, 96 hr. In the model group, the total protein and muc5ac in BALF, the AB-PAS positively stained areas, the muc5ac positively stained granule and the expression of muc5ac mRNA increased beginning at $24 \mathrm{hr}$, increased gradually up to $48 \mathrm{hr}$, peaked at $96 \mathrm{hr}$. The AB-PAS positively stained areas and the expression of muc5ac in airway and lung dynamic change with a synchronization. This result was similar to Chen L et al (Chen et al., 2009) report.

\section{Intervention and dose-effect relationship of Tanreqing injection}

We found that after Tanreqing injection intervention, the indices of airway mucus hypersecretion were reduced to a similar extent as compared with the model group. In contrast, the high dose Tanreqing intervention group exhibited obvious changes. Tanreqing injection effects on airway mucus hypersecretion exhibit a dose-response trend, but the difference between the two groups was not statistically significant. These results imply that the reasons may be existed.

The results of our pre-period study showed that airway inflammation response increased in model group, peaked at $24 \mathrm{hr}$, decreased at $48 \mathrm{hr}$, further declined at $96 \mathrm{hr}$ (Dong et al., 2013). In this study we found that airway mucus secretion also increased in model group, increased at 24 hr, further increased at $48 \mathrm{hr}$, peaked at $96 \mathrm{hr}$. The dynamic changes of the airway inflammatory cytokines were out of sync with airway mucus secretion, and the peak of airway mucus secretion $(96 \mathrm{hr})$ was significantly lags behind the peak of airway inflammation $(24 \mathrm{hr})$. The results suggested that airway mucus hypersecretion was put down to airway inflammation response.

In our previous period, we have done a series of work to explore the mechanism of Tanreqing on AECOPD. The results of our group and other groups found that Tanreqing injection can improve efficacy on AECOPD (Dong et al., 2013; Jiang et al., 2009; Li et al., 2010; Zhong et al., 2010). Tanreqing injection has a certain inhibitory effect on airway mucus hypersecretion. The inhibitory effect of Tanreqing injection possibly through affecting the LPS pathway, but the specific molecular mechanism is unclear. Inhibition of airway mucus secretion mechanism may be through the direct inhibition of mucin or indirect inhibition of mucin production by anti-inflammatory effect. More molecular mechanism details should be investigated in the future.

\section{Conclusion}

Tanreqing injection demonstrates a distinct inhibitory effect on airway mucus hypersecretion induced by LPS in rats. There is a certain dose-effect relationship trend, but relationship is not unclear.

\section{Acknowledgment}

This work was supported by the Program for Innovative Research at the West China School of Medicine, Sichuan University, and Sichuan Technology Department (No. 2012SZ0288).

\section{References}

1. Chen, L., Wang, T., Zhang, J.Y., Zhang, S.F., Liu, D.S., Xu, D., Wang, X., Chen, Y.J. and Wen, F.Q. (2009). Toll-like receptor 4 relates to lipopolysaccharide-induced mucus hypersecretion in rat airway. Arch Med Res. 40 (1): 10-7.

2. Deng, X.L., Zhong, X.G., Zhang, X.J., Zhang, Y.Z., Ren, L.W., Jia, X., Liu, Y.N., and Li, P.T. (2011). The protective role of Tanreqing injection on the immunological liver injury. Zhongguo Zhong Yao Za Zhi. 36 (5): 636-8.

3. Dong, S.J., Zhong, Y.Q., Yang, K., Xiong, X.L., and Mao, B. (2013). Intervention effect and dose-dependent response of Tanreqing injection on airway inflammation in lipopolysaccharide-induced rats. J Tradit Chin Med. 33(4): 505-12. 
Dong et al., Afr J Tradit Complement Altern Med. (2015) 12(3):173-182

http://dx.doi.org/10.4314/ajtcam.v12i3.22

4. Global Strategy for the Diagonsis, Management, and Prevention of Chronic Obstrutive Lung Disease. UPDATED 2013. www.goldcopd.org.

5. Jiang, H.L., Mao, B., Zhong, Y.Q., Yang, H.M., and Fu, J.J. (2009).Treatment of community-acquired pneumonia of randomized controlled trials Tanreqing injection: a system review. Zhong Xi Yi Jie He Xue Bao. 7 (1): 9-19.

6. John, E., Pais, P., Furtado, N., Chin, A., Radhakrishnan, J., Fornell, L., Lumpaopong, A., and Beier, U.H. (2008). Early effects of lipopolysaccharide on cytokine release, hemodynamic and renal function in newborn piglets. Neonatology. 93 (2): 106-12.

7. Lai, H., Rogers, D.F. (2010). New pharmacotherapy for airway mucus hypersecretion in asthma and COPD: targeting intracellular signaling pathways. J Aerosol Med Pulm Drug Deliv. 23 (4): 219-31.

8. Li, W., Mao, B., Wang, G., Wang, L., Chang, J., Zhang, Y., Wan, M.H., Guo, J., and Zeng, Y.C. (2010). Effect of Tanreqing injection on treatment of acute exacerbation of chronic obstructive pulmonary disease with Chinese medicine syndrome of retention of phlegm and heat in Fei. Chin J Integr Med. 16 (2): 131-7.

9. Ou, X.M., Wang, B.D., Wen, F.Q., Feng, Y.L., Huang, X.Y., and Xiao, J. (2008). Simvastatin attenuates lipopolysaccharide-induced airway mucus hypersecretion in rats. Chin Med J (Engl). 121 (17): 1680-87.

10. Rogers, D.F. (2007). Mucoactive agents for airway mucus hypersecretory diseases. Respir Care. 52 (9): 1176-93.

11. Rose, M.C., Voynow, J.A. (2006). Respiratory tract mucin genes and mucin glycoproteins in health and disease. Physiol Rev. 86 (1):245-78.

12. Shi, X.Q. (1989). Medical Laboratory Animal Science, Shaanxi Science and Technology Press. 1989: 422.

13. Wesselius, L.J., Nelson, M.E., Bailey, K., and O'Brien-Ladner, A.R. (1997). Rapid lung cytokine accumulation and neutrophil recruitment after lipopolysaccharide inhalation by cigarette smokers and nonsmokers. J Lab Clin Med. 129 (1): 106-14.

14. Xie,, Y.C., Dong, X.W., Wu, X.M., Yan, X.F., and Xie, Q.M. (2009). Inhibitory effects of flavonoids extracted from licorice on lipopolysaccharide-induced acute pulmonary inflammation in mice. Int Immunopharmacol. 9(2): 194-200.

15. Yanagihara, K., Seki, M., Cheng, P.W. (2001). Lipopolysaccharide induces mucus cell metaplasia in mouse lung. Am J Respir Crit Cell Mol Biol. 24 (1): 66-73.

16. Zhang, Y., Li, T.Q., Wang, G., Chang, J., Mao, B., Wang, L., Chi, H.H., and Wan, M.H. (2004). Tanreqing injection in the treatment of acute exacerbation of chronic obstructive pulmonary disease randomized controlled trial. Evidence Based Medicine. 4 (5): $300-5$.

17. Zhong, Y.Q., Mao, B., Wang, G., Liu, X.M., Diao, X., and Fu, J.J. (2010). Tanreqing injection combined with conventional Western medicine for acute exacerbations of chronic obstructive pulmonary disease: a systematic review. J Altern Complement Med. 16 (12): 1309-19.

18. Zuhdi, A.M., Piazza, F.M., Selby, D.M., Letwin, N., Huang, L., and Rose, M.C. (2000).Muc-5/5ac mucin messenger RNA and protein expression is a marker of goblet cell metaplasia in murine airways. Am J Respir Cell Mol Biol. 22 (3): 253-60. 